\title{
Vaccines: Discrimination, Prejudice, Aggression, and
}

\section{Oppression}

Lisa Marie Portugal*

USA

*Corresponding author: Lisa Marie Portugal, USA, Email: lisamarieportugal@msn.com

\section{Mini Review}

Volume 2 Issue 5

Received Date: June 22, 2018

Published Date: July 16, 2018

\section{Abstract}

Discrimination, prejudice, aggression, and oppression can be factors associated with vaccine clinical trials in poor, developing countries. In addition, once those toxic, damaging vaccines are testing in poor countries, international pharmaceutical companies do not provide the outcome of those tested vaccines for the public they were tested on, but rather are sold and marketed in Western, richer nations. Although, research identifies that vaccines cause paralysis, Cancer, and death, in adults and children, in every global nation they are administered in. In addition, unannounced to the public, vaccines are used to sterilize and genocide populations throughout the world. The medical research available to the public regarding global vaccine damage is: (1) surmounting, (2) unreported by the allopathic medical system, (3) concealed by the pharmaceutical industry, and (4) concealed by colluding global governments.

Keywords: Surmounting; Colluding Global Governments; Behavioral Diversity

\section{Introduction}

The unsuspecting, unknowledgeable, un-researched global public believes and trusts these systems and is not being informed properly and fully about the deadly consequences related to vaccines. This brief literature review serves as a launch pad for: (1) research into discrimination, prejudice, aggression, and oppression on behavioral diversity, (2) health and wellness choices made by individuals or groups, and (3) the role of the health educator related to the global vaccine damage epidemic. The articles, studies, and news items were selected to help individuals, families, and healing service providers influence more positive health behaviors, perceptions, and alternative choices. Health and wellness choices and behavioral diversity of individuals and groups affect every race and the role of the health educator / advocate is to educate and inform a diverse global population.

\section{Objectives}

- Explain behavioral diversity and its impact on health and wellness choices and education.

- Assess the impact of a variety of factors on behavioral diversity, health and wellness choices, and other areas of life.

- Explain the role of the health educator in understanding and responding to behavioral diversity.

\section{Annotated Bibliography}

“The physician who served as Bill Gates' private doctor in Seattle in the 1990s says the Microsoft founder and vaccine proponent "refused to vaccinate his own children" when they were young [1]. "I don't know if he had them vaccinated as adults, but I can tell you he point blank refused to vaccinate them as children," the physician said at a behind closed doors medical symposium in Seattle, adding "They were gorgeous kids, really smart and 


\section{Journal of Natural \& Ayurvedic Medicine}

vivacious, and he said they would be OK as it was, they didn't need any shots." The comments caused a stir among physicians at the symposium with claims he was breaking doctor-patient confidentiality, according to reports. However as he was speaking to other physicians, he was not breaking the industry code of conduct. Gates has three children with his wife Melinda - Jennifer, Rory and Phoebe - born between 1996 and 2002, and according to his former doctor, they are all unvaccinated and healthy. The news that Bill Gates does not vaccinate his own children, despite being the world's most active campaigner for mandatory vaccinations, should come as no surprise. Studies prove that the elite do not vaccinate their children. But at the same time they expect the masses to have their children vaccinated. The elite do not vaccinate. In California, the children most likely to be unvaccinated are white and come from the wealthiest families in Los Angeles, according to a recent study. "Very rich and privileged parents like the idea of herd immunity, but they don't want to take the risks associated with vaccinations when it comes to their own children. They are worried about adverse reactions including autism" ( $p$. 1).

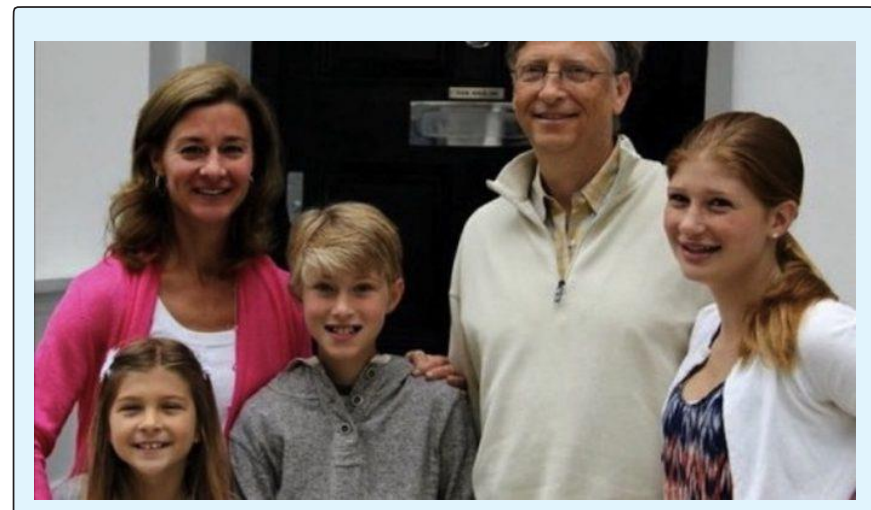

Figure 1: Bill Gates' non-vaccinated children.

Why can Bill Gates get away with not vaccinating his children, yet many children are being medically kidnapped by the government in states all across
America? In addition, mothers and children are being hunted down for vaccinations against their will in countries like Africa, Thailand, Brazil, and many others. Google Bill Gates Eugenicist [2].

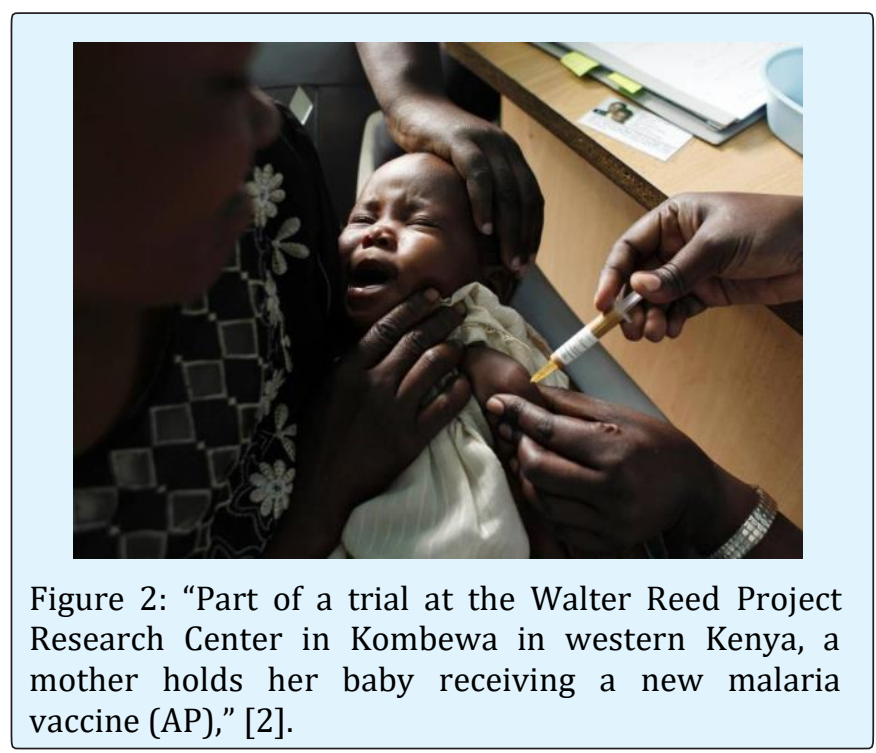

Revealing news from the (WHO) World Health Organization, countries in Africa which include Malawi, Kenya, and Ghana are the testing ground for the world's first malaria vaccine. Young black children, who are at the highest risk of death in Africa, are the target of the injectable malaria vaccine piloted by the pharmaceutical company GlaxoSmithKline. In addition to GlaxoSmithKline, the perpetrator of the toxic, deadly malaria vaccine, funding also comes from the following vaccine global alliance: (1) the Global Fund to Fight Aids, Tuberculosis, and Malaria, (2) UNITAID, and (3) GAVI [2]. The Middle East, Latin America, and Southeast Asia have also been targeted as "malaria cases" [2]. Children five to 17 months old are being tested on in clinical trials with this toxic disease-laden concoction. The countries are delivering the vaccine through the existing Bill Gates vaccination programs [2].

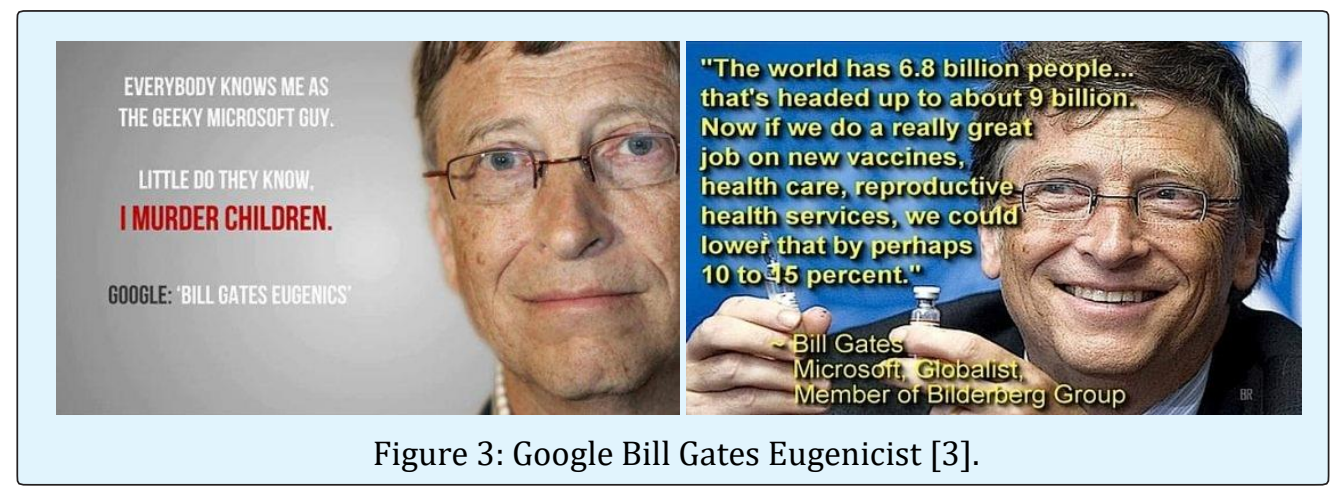

Lisa Marie Portugal. Vaccines: Discrimination, Prejudice, Aggression, and Oppression. J Nat Ayurvedic Med 2018, 2(5): 000139. 


\section{Journal of Natural \& Ayurvedic Medicine}

African continues continue to be used by international, globalist, corporate, pharmaceutical, banker, multigovernment alliances as an experimentation ground for deadly, heinous agendas, the recent of which happens to be microchip implants. These experiments on Africans are being perpetrated to inject biometric, trackable, traceable, surveillance technology cards useful to governments, technology companies, medical systems, and merchandising corporations.

"According to Patriot Truther and BusinessWire, credit card company Visa recently introduced a new specification for the use of biometrics with chip card transactions that can enable palm, iris, facial or voice biometrics. The first-of-its-kind technology is designed to be incorporated for use with the EMV® (Europay, MasterCard, Visa) chip industry standard to ensure the cards can be used around the globe" [3].

"There is increasing demand for biometrics as a more convenient and secure alternative to signatures or PINs, especially as biometrics technologies have become more reliable and available," claimed Mark Nelsen, senior vice president of Risk Products and Business Intelligence for Visa Inc. "However, to support wide adoption, it is equally important that solutions are scalable and based on open standards. Building on the EMV chip standard provides a common, interoperable foundation, as well as encourages innovation in cutting-edge biometric solutions" [3].

"The idea that Ebola might be a genetically engineered bioweapon was openly discussed by a top Liberian scientist named Dr. Cyril Broderick, who published a front-page story in the Liberian Observer containing the astonishing statement, "Ebola is a genetically modified organism (GMO)." ...Broderick goes on to assert that the U.S. Dept. of Defense has been using African women and children for bioweapons experiments. In his own words, he talks about "...the existence of an American MilitaryMedical-Industry that conducts biological weapons tests under the guise of administering vaccinations to control diseases and improve the health of black Africans overseas" [3].

A sterilization chemical causing miscarriages found in tetanus vaccines have been administered to young women in Kenya. This deliberate, subversive, and cruel act perpetrating medicine and medical care was coordinated by criminal cartels known as the World Health Organization (WHO) and UNICEF. Red flags were raised when it was revealed this "so-called tetanus vaccine" had an extremely odd inoculation schedule. The perpetrators of the vaccine enforced a two year schedule with five shots. Tetanus vaccines do not require that type of schedule [4].

"We sent six samples from around Kenya to laboratories in South Africa. They tested positive for the HCG antigen," Dr. Muhame Ngare of the Mercy Medical Centre in Nairobi told LifeSiteNews. "They were all laced with HCG" [4].

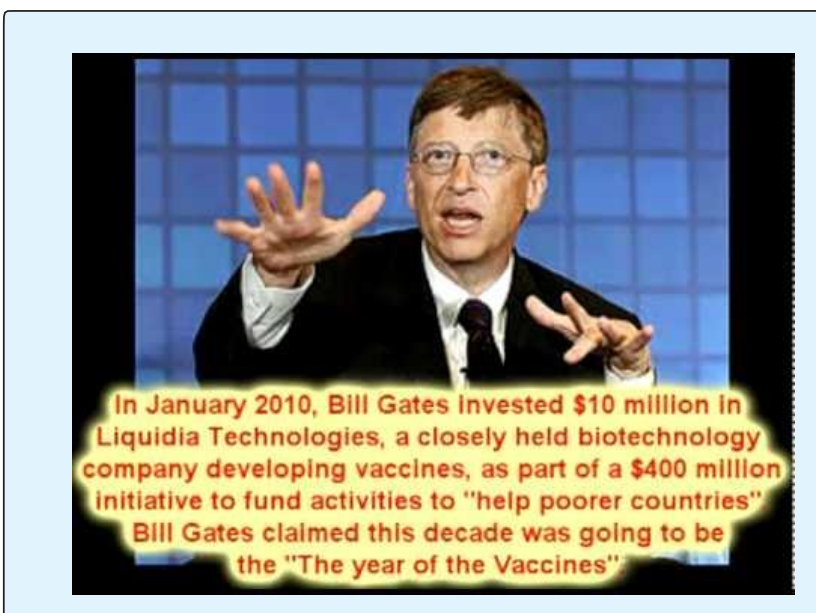

Figure 5: Bill Gates claimed dacade-The year of vaccines.

The wrong strains of Gardasil are being used to vaccinate black women. Scientists from Duke University School of Medicine have found that the Gardasil vaccine is completely worthless for African American women [5]. Yet, many African American women are still being vaccinated by allopathic doctors with this toxic and deadly serum despite the published and well-known data. Women, men, and children of all ages and races are being injected and infected with this deadly, cancerous vaccine and being permanently damaged, paralyzed, and dying. The allopathic medical community and corporate, profiteering pharmaceutical companies are concealing the statistics from the public as often as they can. Furthermore, allopathic doctors are not informing their patients about the serious and deadly risks associated with this vaccine and continue to vaccinate those they serve.

The World Health Organization (WHO) is well-known for vaccine experimentation and trials on humans in developing countries [6]. Trails are testing in poor, developing countries before administering to the public in Western countries. Poor, non-Westernized countries such as Thailand and Brazil are always used as guinea pigs because fewer ethical questions are asked and testing is 


\section{Journal of Natural \& Ayurvedic Medicine}

cheaper [6]. Once toxic testing is completed, the vaccines become too expensive for those same countries to afford. Although toxic vaccine testing is prevalent in poor developing countries, clinical trials of vaccine strains prevalent to Africa and others are not profit-appealing to drug companies [6].

The title of Dr. Stephanie Seneff's talk in this video is called "Vaccines and Glyphosate a Toxic Combination" [7]. Dr. Seneff reviews the toxic, poisonous, damaging, Cancerous affects of MMR vaccines and its relationship to Glyphosate, Autism, and aluminum. A 49 minute talk on the real facts related to vaccine damage from a peerreviewed published, medical expert, researcher, and doctor. Dr. Seneff explains that the great doctors of the world know the medical theory of immunization and contagious a disease is as false as false can be, but they dare not speak out. Furthermore, as long as vaccines make money for those who sponsor it, and if people can be persuaded into believing it, there will be no change. She highlights that quote was written in 1970 and the public is still being damaged by and lied to about vaccines today.

\section{Conclusion}

In closing, this literature review is merely a short summary of a few articles and cannot encompass the surmounting studies and medical news regarding the damaging affects of vaccines in poor, developing countries, Western nations, and globally. Although there is a great deal of data, statistics, and medical research supporting findings that vaccines are paralyzing, causing Cancer, and killing children and adults, allopathic doctors, profiteering, pharmaceutical companies, and global governments are concealing the evidence. This literature review summarizes implications for health and wellness advocates, educators, and healing medical practitioners to inform, educate, and provide detox services to the public. Areas for further study can include vaccine and Cancer detox research, methods, services, and service providers. Additionally, naturopathy and Traditional Chinese medicinal and detox providers can be identified to help affected adults, children, families, and communities find the necessary resources to receive help and healing. Finally, the PEN-3 Model can be used by health educators and healing practitioners to address: (1) issues related to a sense of inevitability, stigma, and denial, (2) an overall lack of knowledge regarding wellness and health, (3) a lack of culturally sensitive materials, (4) communication issues with health care providers, and (5) influence of family on perceptions and behaviors $[8,9]$.

\section{References}

1. Dmitry B (2018) Bill Gates' former doctor says billionaire 'refused to vaccinate his children.' YourNewWire.com.

2. Anna C (2017) Three African countries chosen to test world's first malaria vaccine: Ghana, Kenya and Malawi to begin pilot scheme trialling experimental treatment next year. The Independent Online.

3. Heyes JD (2015) Africa is the Western world's testing ground for microchip implants, weaponized viruses and experimental vaccines.

4. Adams M (2014) Tetanus vaccines found spiked with sterilization chemical to carry out race-based genocide against Africans.

5. Shilhavy B (2017) Gardasil vaccine victims: "I just believed everything the doctor told me." Health Impact News.

6. No authors listed (1994) Should developing countries be testing grounds for vaccines rejected by the USA? AIDS Anal Afr 4(4): 2.

7. Stephanie Seneff (2018) Vaccine Choice Canada on vaccines, Toronto, March 27, 2018 (VIDEO).

8. Cowdery JE, Parker S, Thompson A (2010) Application of the PEN-3 Model in a Diabetes prevention intervention. Journal of Health Disparities Research and Practice 4(1).

9. Stephanie Seneff. Information on Glyphosate (Roundup).

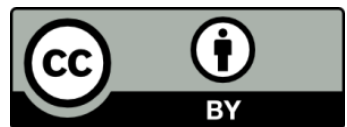

